\title{
Web curriculo e UCA: onde se cruzam as perspetivas de investigadores e formadores
}

\author{
Altina Ramos; Maria Elizabeth Almeida \\ Instituto de Educação- Universidade do Minho; Potificia Universdiade Católica de São Paulo- Brasil
}

\begin{abstract}
Resumo
O conceito de web curriculo desenvolvido por Maria Elizabeth Almeida (2010) e definido por Almeida e Valente como "processo no qual as TDIC se encontram imbricadas no desenvolvimento do currículo em atividades pedagógicas, nas quais professores e alunos se apropriam destas tecnologias e as utilizam para aprender, como se elas fossem invisíveis" (2012, p. 59) enforma o trabalho de pesquisa dos investigadores do Programa de Pós-Graduação em Educação: Currículo, da Pontifícia Universidade Católica de São Paulo-Brasil (PUC - SP). Alguns destes investigadores são também formadores de professores integrados no Projeto "Um Computador por Aluno" (UCA). Este artigo apresenta as perspetivas concetuais desses investigadores acerca do uso educativo das tecnologias digitais e aponta, muito brevemente, para comparações com as suas práticas em termos de formadores no contexto UCA.
\end{abstract}

Palavras-chave: Formação de professores; integração curricular das TIC; web curriculo;

\section{Introdução}

Tanto o uso de tecnologias digitais em contexto escolar como a formação dos professores que com elas trabalham são assuntos recorrentes hoje em dia. Uma das marcas distintivas nesse panorama é a qualidade da formação dos formadores dos professores, por um lado, e, por outro, a estratégia de formação e acompanhamento dos docentes que no dia-a-dia da escola integram as TIC nas suas práticas p pedagógicas.

Neste artigo centramo-nos nos formadores do Programa UCA, simultaneamente investigadores (docentes, mestrandos e doutorandos) integrados no Programa de Pós-Graduação em Educação da PUC-SP.

No contexto de um estágio junto desta equipa de investigadores, foi realizado um estudo de natureza exploratória e interpretativa para conhecer as conceções e as práticas acerca da utilização educativa das TIC em distintos níveis e contextos. Neste artigo, e por limitações de espaço, apresentamos de forma integral os resultados relativos às conceções desses investigadores e referimos muito brevemente as suas práticas de formação de professores, assunto que será objeto de outro artigo.

\section{Enquadramento contextual e teórico: Web Currículo e Projeto UCA}

A era digital em que vivemos caracteriza-se, entre outros fatores, por um grande desenvolvimento tecnológico que tem impacto no dia a dia da vida do ser humano. Desde cedo as crianças utilizam recursos digitais de modo muito intenso e natural brincando, descobrindo e aprendendo em contexto informal. No entanto, "ainda não observamos nos processos de ensino e de aprendizagem, em distintos níveis, do Básico ao Superior, os mesmos impactos e transformações visivelmente identificados" (Almeida \& Valente, 2012). Cabe pois à escola, e portanto aos professores, orientar esse processo no sentido de perspetivar as tecnologias como ferramentas cognitivas (Jonassen, 2007) de modo a desenvolver nas crianças, desde cedo, o pensamento reflexivo, crítico e criativo fundamentais para formar cidadãos capazes de procurar e localizar informação, compreendê-la e tratá-la transformando-a em conhecimento. Este é também um modo de superar paradigmas de aprendizagem baseados na reprodução, memorização e fragmentação de informação, que já não são adequados às exigências da atual Sociedade de Informação e Comunicação. Nesta linha de pensamento, encontramos o conceito de web curriculo desenvolvido por Maria Elizabeth Almeida e definido por Almeida e Valente "como sendo um processo no qual as TDIC se encontram imbricadas no desenvolvimento do currículo em atividades pedagógicas, nas quais professores e alunos se apropriam destas tecnologias e as utilizam para aprender, como se elas fossem invisíveis" (2012, p. 59). Desde 2008, Maria Elizabeth Almeida e o seu grupo de pesquisa na PUC-SP vêm intensificando o trabalho nesta área tanto em termos investigativos com grupos de pós-graduação como na sua implementação na formação de vários agentes educativos, particularmente professores, alunos e gestores escolares. Na PUC-SP o Projeto de pesquisa UCA CNPq (Almeida, 2013) respeita os princípios gerais do UCA orienta-se para o currículo da escola do século XXI centrando a sua atuação na integração das TIC ao currículo basedo nos pricipios de inovação, conhecimento científico e aprendizagem. Sete Escolas integram esse projeto: três do Estado de São Paulo, duas de Góias e duas de Tocantins, sendo as Unibersidades Formadoras PUC-SP, Universidade Federal de Goiás (UFG) e Universidade Federal de Tocantins (UFT). O grande objetivos do projeto coordenado pela PUC - SP é desenvolver um processo de investigação-formação-ação contextualizado na realidade da escola e na prática pedagógica para impulsionar o uso do laptop de modo que este traga contribuições significativas ao currículo. As Universidades formam pesquisadores para o efeito que, 
nas Escolas, fazem a formção de gestores, professores, alunos, especialistas das redes de ensino e pais. As atividade de formação têm dois eixos preponderantes: uso do laptop para transmitir informações sobre o conteúdo planeado, fazer exercícios de fixação, jogar e apresentar trabalhos; atividades voltadas à aprendizagem por meio de experiências, resolução de problemas e desenvolvimento de projetos, que propiciam aos alunos a expressão do pensamento e a autoria.

“O web currículo (...), representa a integração curricular abrangendo a tecnologia e toda sua multiplicidade de linguagens. O mundo mudou, a educação mudou, é preciso investir no funcionamento das redes de ensino" (Almeida, 2014, s.p.)

Ainda em palavras da autora

web currículo representa a integração curricular abrangendo a tecnologia e toda sua multiplicidade de linguagens. Temos que pensar nos recursos abertos, no potencial de criação de novas interfaces e recursos utilizados pelos estudantes e na força do trabalho colaborativo que pode expandir o conhecimento para outros estados, outros países. O espaço da escola não é mais o único lugar de produção do conhecimento. A web trouxe a cultura dos museus e laboratórios virtuais e os alunos podem navegar em qualquer museu do mundo, realizar experiências e simulações e não apenas fazer as visitas programadas a esses espaços, o que nem sempre é viável (2014,s.p)

São estes alguns dos principios teóricos do web curriculo que estão subjacentes ao Projeto UCA que visa a inclusão digital, a inovação na educação através da mudanças das metodologias da prática pedagógica e na abertura do currículo ao que emerge no ato educativo, de modo a criar melhores condições de aprendizagem e, por esta via, a promoção do sucesso escolar.

O projeto foi concluído em 2013 e, Almeida refere que o UCA

teve como objetivo principal identificar as contribuições e dificuldades das ações de formação e das práticas realizadas nas escolas participantes do Projeto UCA, as mudanças no currículo e nas práticas educativas, os indícios de inovação educativa. A pesquisa revelou a necessidade de mudanças nos currículos tradicionais e nas práticas escolares para acompanhar as mudanças provocadas pela tecnologia no cotidiano dos alunos" (2013, s.p)

\section{Metodologia}

\section{Participantes}

O grupo atrás referido era composto por oito investigadores à data de recolha de dados, janeiro de 2014. Sete deles eram simultaneamente formadores do Projeto UCA.
Tratou-se de uma amostragem teórica amostragem teórica típica da grounded theory que visa não a representatividade da amostra, mas a "representatividade dos conceitos" (Strauss \& Corbin, 1990, p.190): o investigador escolher situações e pessoas na área do estudo com o objetivo de identificar, desenvolver e relacionar conceitos.

\section{Instrumento de recolha de dados}

A recolha de dados foi feita através de inquérito por questionário de resposta aberta com cinco grupos de questões. O grupo I destinava-se à caracterização da amostra em termos de formação académica e formação específica para o uso das Tecnologias digitais, tempo de experiência profissional na área do estudo e atividade profissional atual. Os grupos II e III, através de perguntas diversas e complementares, tinha como objetivo conhecer as conceções teóricas destes investigadores acerca da utilização educativa das tecnologias digitais. O grupo IV centrava-se nas práticas de formação desses investigadores, enquanto formadores UCA da PUC-SP, e o grupo V pretendia estudar as mudanças mas práticas do ponto de vista do investigador/formador. Esta parte do questionário não é tratada neste artigo.

A análise dos dados baseou-se nas técnicas sugeridas pela grounded theory com apoio do software NVivo10: os sujeitos foram caracterizados, através da função Classificações quanto à formação académica e formação específica para o uso das tecnologias digitais; tempo de experiência profissional e atividade profissional atual. Procedemos depois à primeira etapa da análise, a "codificação aberta - processo de segmentar os dados, examiná-los, compará-los, conceptualizá-los e categorizá-los" (Strauss \& Corbin, 1990, pp. 60-61). Deste processo resultaram nove categorias emergentes dos dados: Autonomia do professor-formando; Colaboração entre pares e entre professor-alunos; Reflexividade do professor-formando; formação contextualizada $e$ in loco; Inclusão digital; Interação curricular das TIC; Mobilidade; Redes de aprendizagem; Outros. A seguir, estas categorias foram integradas em duas categorias conceptualmente superiores: Conceções dos investigadores acerca da utilização educativa das tecnologias digitais e Práticas de formação quanto a utilização educativa das tecnologias digitais. Trata-se da codificação axial (Strauss \& Corbin, 1990) que visa a reestruturação dos dados já codificados através da codificação aberta.

Depois de analisado o corpus, foram aplicadas funções de questionamento e de visualização que favorecem a compreensão da análise. Neste artigo referimo-nos a Frequência de palavras, Pesquisa de palavras e a Modelos que apresentamos no tópico seguinte.

\section{Apresentação e interpretação de resultados}

\section{Caracterização da amostra}

Foram oito os respondentes. Havia grande diferença entre eles quanto ao número de anos de experiência na 
área de trabalho em causa. Três pessoas tinham entre três e seis anos e outras três entre 10 e 13 anos; dois tinham vinte ou mais anos de experiência.

Apesar de a formação inicial destes investigadores ser diversa tanto em relação à área curricular quanto ao grau académico, todos tinha formação específica para o uso educativos das TIC na prática pedagógica, obtida predominantemente no contexto do Programa de Pós-Gradução em Educação: Currículo, da PUC-SP. De igual modo, no momento da recolha de dados, a investigação de todos os respondentes estava relacionada com o uso das TIC na prática pedagógica. À exceção de um, todos eram formadores do programa UCA.

\section{Das palavras às ideias}

Começamos por situar as ideias gerais expressas pelos respondentes através da nuvem que expressa a frequências de palavras

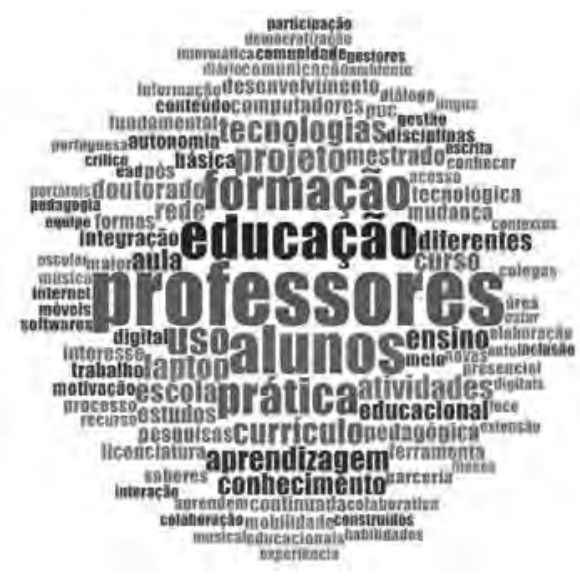

Figura 1. Nuvem da frequência de palavras das respostas

Sem surpresa, verificamos que as palavras de mais elevada frequência são aquelas cujo significado remete para a problemática em estudo: professores (47) alunos (34) educação (31) formação (27) prática (24) uso (20) projeto (17) currículo (15) tecnologias (15) laptop (14). De facto, o foco da intervenção dos investigadores/formadores era, em, primeiro lugar, os professores e logo a seguir os alunos. Vemos agora o contexto da palavra uso para confirmarmos que, à exceção de uma, todas as ocorrências se referem, de facto, ao uso de tecnologias digitais. Basta clicar numa das linhas à esquerda ou à direita da palavra "uso" para acedermos ao contexto restrito e amplo da palavra, função muito útil do NVivo já que em investigação qualitativa o contexto é sempre importante, senão mesmo determinante.

De salientar que há cerca de 300 palavras com apenas uma ocorrência o que indica que, apesar de uma estreita proximidade conceptual quanto ao uso das TIC, a expressão das ideias de cada investigador foi original, sem lugares comuns.

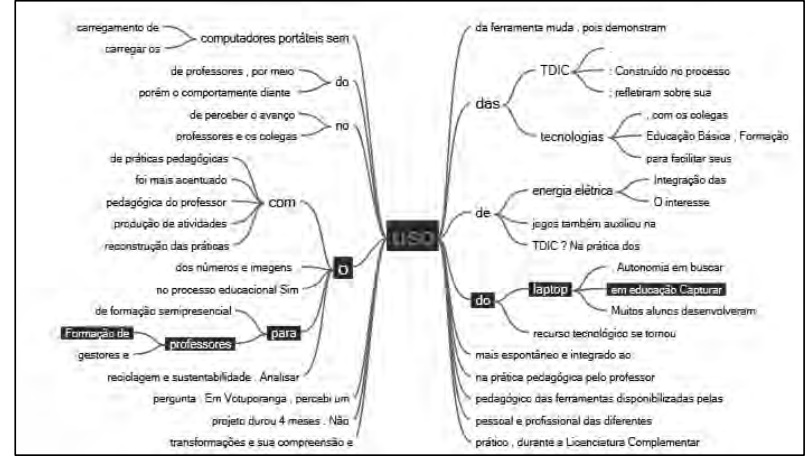

Figura 2. A palavra "uso" em contexto

\section{Conceções acerca do uso educativo das TIC}

A figura abaixo mostra as nove subcategorias da categoria conceções dos investigadores quanto ao uso educativo

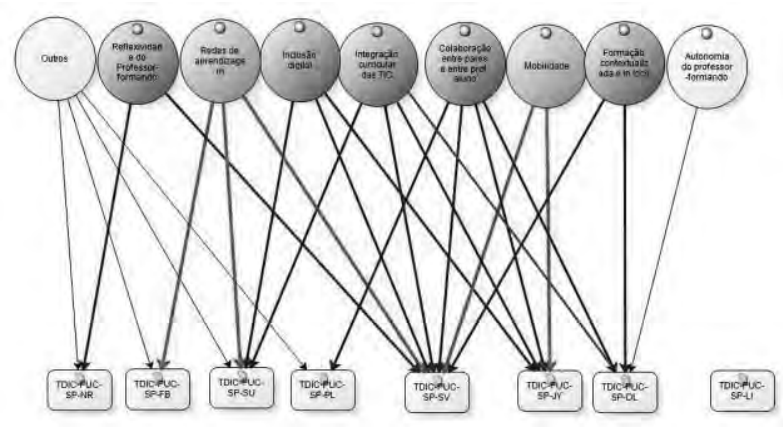

Figura 3. Conceções acerca do uso educativos das TIC

Os círculos representam as categorias de análise e os retângulos as fontes, ou seja os questionários. Um dos respondentes (último retângulo à direita) não se manifestou quanto a conceções, embora o tivesse feito depois quanto a práticas. As setas indicam que respondentes se referiram ao conceito da respetiva categoria.

A cor azul representa as categorias identificadas mais vezes e por mais pessoas e que coincidem com as linhas teóricas subjacentes ao Web curriculo; a vermelha representa o que consideramos serem abordagens que emergiram mais na última fase de implementação do projeto UCA, também devido à evolução da tecnologia, e a rosa se refere a categoria outros e autonomia do professor-formando por terem pouca expressão no corpus analisado.

Ilustramos agora, com palavras dos investigadores algumas das categorias identificadas: quando se referem a Integração curricular das TIC os investigadores falam de "formação continuada de professores, gestão das TDIC e sua integração ao currículo” (ITDIC-PUC-SP-DL); “Currículo, Integração (...) integração das TDIC ao currículo (TDIC-PUC-SP-JY); "investigar as contribuições e os indícios de inovação no ensino e aprendizagem dos alunos de educação básica, nas escolas brasileiras, 
pela inserção do laptop educacional às práticas pedagógicas. (TDIC-PUC-SP-SV). Fica, pois claro, que a perspetiva não é a de acrescentar tecnologia às atividades das crianças, mas a de a integrar nessas práticas, ou seja, em palavras de Alves (2014, p. 102), também investigador do grupo Web curriculo, "o uso do tablet em sala de aula não deve ser instrumentalizado como "brinquedinho", mas tomado como recurso educacional que possui ...papel pedagógico de auxiliar a aprendizagem"

A Colaboração entre pares e entre professor-alunos é recorrente nas palavras dos investigadores inquiridos: "estudos realizados nas escolas UCA revelam que os professores aprendem mais com os colegas de profissão"; a inovação se enriquece com o intercâmbio de práticas pedagógicas, o diálogo reflexivo, os estudos e a reconstrução das práticas com o uso das tecnologias, com os colegas de profissão. (DIC-PUC-SP-SV); “ os alunos ajudavam os professores e os colegas no uso do laptop". (DIC-PUC-SP-PL); [o que considero mais importante é] o registro $e$ compartilhamento das práticas ... parceria entre professor e aluno"'(TDIC-PUC-SP-DL).

A nosso ver, uma das marcas mais distintivas do projeto UCA orientado pela PUC-SP foi o facto de centrar a formação nas necessidades concretas das escolas e dos professores a quem se dirigia o que implicava que os formadores conhecessem bem os contextos e estudassem a melhor estratégia de formação para cada situação em que intervieram. A isto se refere a categoria Formação contextualizada $e$ in loco. Em palavras dos investigadores: [valorizei] " $a$ formação no contexto do professor, ou seja, na própria escola"; (TDIC-PUC-SP-DL);"Currículo do curso de formação semipresencial para o uso das TDIC construído no processo da formação; contextualizado à prática do professor "'(TDIC-PUC-SP-SV).

A Inclusão digital, um dos grandes objetivos do Projeto UCA, está presente tanto no pensamento dos investigadores estudados como no de Maria Elizabeth Almeida, mentora do Projeto de pesquisa UCA, desenvolvido pela PUC-SP. Ao ser questionado sobre a grande finalidade do uso das TDIC na Educação, um dos investigadores refere "favorecimento da aprendizagem na cultura digital (TDIC-PUC-SP-JY) e outro "[temos de intervir] de modo que a escola acompanhe a evolução tecnológica em geral e o aluno tenha maior possibilidade de ingresso no mercado de trabalho". (TDIC-PUC-SP-SU). Esta é também uma preocupação de Almeida e Silva (2011, p. 7) "a inclusão das TDIC na educação demanda políticas públicas voltadas para a inclusão social e para a inserção da população na sociedade digital". Mais tarde, concretamente no relatório final do projeto UCA da PUC-SP, Almeida (2013, p. 21) considera que "no que se refere aos impactos, a pesquisa evidenciou a inclusão digital de professores, alunos e famílias nos casos em que o laptop era levado para casa".

A Reflexividade do professor-formando é também uma das intenções da equipa de formadores, como referem alguns deles: "a formação que acontece na escola também ajuda o professor a refletir sobre a própria prática” (TDIC-PUC-SP-NR); “a partir da auto-análise o professor poderá verificar o grau de integração das TDIC que aplica na sua prática pedagógica para procurar aperfeiçoar e ampliar o seu conhecimento por meio de cursos de formação (TDIC-PUC-SP-NR); "A inovação se enriquece com o intercâmbio de práticas pedagógicas, o diálogo reflexivo, os estudos e a reconstrução das práticas com o uso das tecnologias, com os colegas de profissão. (TDIC-PUC-SP-SV).

A mobilidade e as Redes de aprendizagem são preocupação da mentora do Projeto: "o uso das TDIC em Educação, em especial das tecnologis digitais portáteis representadas por distintos dispositivos tecnológico com características de mobilidade e conexão à internet, alem de menor custo para aquisão representa possivel abertura para a aprendiagem, o ensino e o desenvolvimnro do curriculo (Almeida, 2014 , s.p). Também alguns investigadores referem estes aspectos. Um deles repete várias vezes nas suas respostas a importância da "Rede colaborativa de aprendizagem",'"Rede colaborativa de aprendizagem a partir de projetos comuns, comunidades em rede aprendem pelo diálogo reflexivo crítico"; Rede Colaborativa de aprendizagem - EaD: a extensão da formação continuada dos professores se prolonga no ambiente a distância. No ambiente AVA os professores continuam os estudos que iniciaram na formação presencial". (DIC-PUC-SP-SV). Outros, usando terminologias diferentes referem as "comunidade de Prática" de modo quase sistemático, (DIC-PUC-SP-FB) e o "estar junto virtual (Valente)" (TDIC-PUC-SP-SU).

$\mathrm{Na}$ categoria Outros, os investigadores referiram conteúdos que, embora podendo ser relacionados com os apresentados nas categorias anteriores, também podem ser vistos como autónomos e relacionados com os seus contextos específicos de trabalho. Assim, surgem, entre outros "organização e foco de cursos de formação de professores em TDIC"; "motivação intrínseca e extrínseca (vide as atuais teorias de motivação educacional) dos alunos e professores" TDIC-PUC-SP-SU); "[meio de] "facilitar a aprendizagem" e "Ensinar cidadania" (TDIC-PUC-SP-PL); "Auxiliar no processor de ensino e aprendizagem do aluno, facilitando determinadas situações de ensino, o acesso à informação, democratizando o conhecimento. (TDIC-PUC-SP-NR)

\section{Conclusão}

Os resultados apontam para quatro tendências: a) as conceções dos investigadores acerca da utilização educativa das TDIC não dependem da sua formação inicial nem da formação para o uso educativo de TDIC na prática pedagógica e são também independentes do seu tempo de atuação nesta área. Os seus interesses de investigação articulam-se com as suas práticas de formação de professores no contexto do projeto UCA. As suas conceções acerca da utilização educativa das tecnologias centram-se em cinco grandes áreas: inclusão digital; integração curricular das tecnologias digitais; autonomia e reflexividade do professor/formando; comunicação e colaboração entre 
pares e entre professor/aluno; formação contextualizada e "in loco" e dependente dos interesses do professor. Emergem as temáticas da mobilidade e das redes de aprendizagem como áreas a desenvolver.

As práticas de formação destes
investigadores-formadores respeitam, de um modo geral, as conceções referidas acima. Porém, a categoria "Outros" surge agora com muito maior relevo já que cada investigador apresenta novos ideias decorrentes, pensamos, das características dos contextos de formação em que atuam.

Verificamos que tanto as conceções como as práticas destes investigadores estão em sintonia com as perspetivas teóricas constituintes do conceito de web currículo, havendo algumas ideias emergentes relevantes para a evolução do trabalho do grupo de pesquisa.

\section{Referência Bibliográficas}

Almeida, M. E \& Silva, M. G. (2011). Currículo, Tecnologia e Cultura Digital: Espaços e Tempos de Web currículo. e-curriculum 7 (1) Disponivel em http://revistas.pucsp.br/index.php/curriculum.

Recuperado em janeiro de 2013.

Almeida, M. E. \& Valente J. A. (2012). Integração Currículo e Tecnologias e a produção de narrativas digitais. Currículo sem Fronteiras, 40 (3), 57-82.
Almeida, M. E. (2010). Integração de currículo e tecnologias: a emergência do web curriculo. In Anais do XV Endipe - Encontro Nacional de Didática e Prárica de Ensino. Belo Horizonte: UFMG

Almeida, M. E. (2014). Web currículo: a convergência digital é o futuro (entrevista). Disponível em http://www.abrelivros.org.br/home/index.php/noticia s/5597-web-curriculo-a-convergencia-digital-e-o-fut uro. Recuperado em maio de 2015

Almeida, M. E. (Coord.) (2013). Relatório Técnico Científico: O currículo da escola do século XXI integração das TIC ao currículo: inovação, conhecimento científico e aprendizagem (documento policopiado de circulação interna)

Almeida, M. E., Alves, R. M., \& Lemos, S. D. (Orgs) (2014). Web curriculo: aprendizagem, pesquisa e conhecimento com o uso de tecnologis digitais. Rio de Janeiro: Letra Capital.

Strauss, A. \& Corbin, J. (1990). Basics of qualitative research - Grounded theory procedures and techniques. London: Sage.

\section{Agradecimentos}

Agradecemos à FCT a Bolsa de Pós doutoramento (SFRH/BSAB/1339/2013) concedida à primeira autora 